\title{
Lesser Tuberosity
}

National Cancer Institute

\section{Source}

National Cancer Institute. Lesser Tuberosity. NCI Thesaurus. Code C32983.

The anterior tubercle on the humerus neck where the subscapularis tendon inserts. 